\title{
Regulating cellular stress responses: an emerging strategy for rational metallodrug design
}

\author{
Xiaoda Yang*,1 \\ ${ }^{1}$ State Key Laboratories of Natural \& Biomimetic Drugs \& Department of Chemical Biology, School of Pharmaceutical Sciences, \\ Peking University Health Science Center, Beijing, PR China \\ * Author for correspondence: Tel.: + 86108280 5611; xyang@bjmu.edu.cn \\ ' In conclusion, we postulate that for future research into metal-based pharmaceuticals, a \\ successful strategy may favor prodrugs targeting the cellular stress responses, with ligands helping \\ to deliver metal ions to target proteins."
}

First draft submitted: 18 October 2017; Accepted for publication: 20 December 2017; Published online: 13 February 2018

Keywords: cell stress response $\bullet$ metallodrug $\bullet$ speciation

Metal-based drugs have been an appealing target for medicinal chemists since the success of cisplatin in 1970s [1]. Metallodrugs exhibit indispensable pharmacological activity due to their structural diversity (Figure 1A), including specific coordination geometry for better target recognition, dynamic bond formation and using residual coordination sites or key ligands to facilitate specific binding to the target.

However, metals lack specificity in interactions, meaning that toxicity remains the dark cloud over the development of metallodrugs. As recently indicated by Levina et al. [2], compared with organic equivalents, transition metal speciation under biological conditions is complicated through the reactivity of many metal complexes and the complexity of the biological media. Metal complexes in the body may undergo aquation, hydrolysis or other ligand-exchange reactions, redox reactions and electrostatic/hydrophobic protein binding (often as a precursor to covalent bonding via ligand exchange). These changes can cause drugs to become inactive or metal toxic, and can lead to incorrect or unreliable conclusions about their biological activities.

\section{Strategy for rational metallodrug design}

As such, there is a need for a novel strategy for rational metallodrug design to help to overcome these issues. It can be observed that the biological behavior of a nonessential metal ion relates to the similarity of an essential metal ion as reference, known as the 'the analogy principle' [3]. Inside the cells, there exists intrinsic metal-sensing (or metalregulated) systems triggering intracellular signal transductions. If a nonessential metal ion mimics or promotes the intrinsic metal signaling, it will likely have positive effects, otherwise, negative effects will be observed. Nonessential metals can produce both positive and negative effects, depending on the degree of deviation from the reference metal ions in charge, ionic radius, coordination number, coordination stability, redox potential, etc. We postulate that metal complexes exhibit pharmaceutical effects through the natural repair pathways of the cells, in other words, the cellular stress response systems, according to the analogy principle.

Cells respond to stress in a variety of ways, depending on the level and mode of stimulus [4]. Upon a stressful stimulus, the cell's initial response attempts to defend against and recover from injury. However, if survival efforts fail, programmed cell death (apoptosis) can be activated to prevent further harm.

Cell stress response can be triggered by either damaged proteins (unfolded/misfolded proteins or protein oxidation), or by the changes of certain intracellular messengers, such as ATP and reactive oxygen species. Metal ions, such as $\mathrm{Ca}^{2+}, \mathrm{Zn}^{2+}$ and $\mathrm{Cu}^{2+}$, regulate a variety of stress responses, including unfolded protein response [5,6], heat shock response [7,8], antioxidant response [9,10] and DNA damage response [11]. Many of these are not 


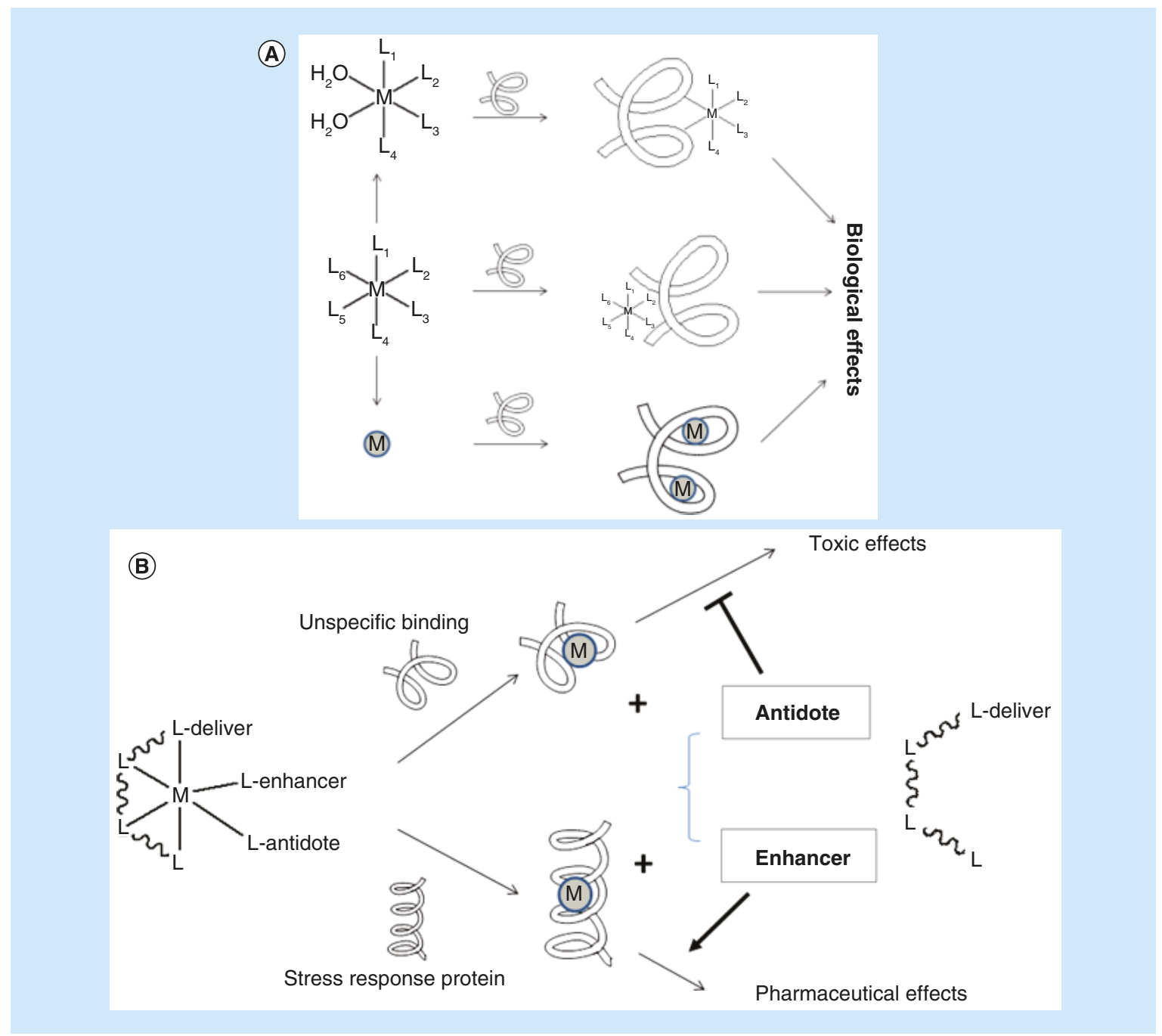

Figure 1. (A) The action of metal-based medicinal complexes and (B) a proposed strategy of designing metal-based prodrugs regulating the cellular stress responses. Since cellular stress response proteins may exhibit high specific interactions with intrinsic metal ions, metal complexes should be prodrugs with multifunctional ligands for specific metal delivery, releasing antidotes and enhancers that are incorporated as ligands.

conventional metalloproteins, such as $\mathrm{Hsp} 60$ with $\mathrm{VO}^{2+}{ }_{[7,12],} \mathrm{HspA}$ with $\mathrm{Ni}^{2+}$ and $\mathrm{Bi}^{3+}[8]$, and multiple antibiotic resistance regulator with $\mathrm{Cu}^{2+}[9]$.

\section{Examples of platinum \& vanadium metallodrugs}

Vanadium compounds exhibit potent hypoglycemic effects in vitro and in vivo and have shown success in treating metabolic syndromes, making them promising antidiabetic agents [13,14]. It has been shown that vanadyl ions bind to the Hsp60, inducing Hsp60-PPAR- $\gamma$ protein interaction. Downstream, this can trigger upregulation of the PPAR- $\gamma$ levels in adipocytes, muscle cells and pancreas $\beta$ cells, activating AMPK signaling, the stimulation of adiponectin, and the suppression of JNK activity $[7,12,15,16]$. Vanadyl ions may also upregulate Bip/Grp78 and decrease the expression of $\mathrm{CHOP}$ in pancreatic $\beta$ cells upon free fatty acid stress [5], and inhibit aggregation of human islet amyloid polypeptide [17]. These findings indicate that vanadium enhanced stress adaption of cells through regulation of unfolded protein response may be a molecular basis for $\beta$-cell protection in antidiabetic vanadium compounds.

The mechanism for cisplatin may involve activating p 53 directly or through ATM/ATR signal transduction [11]. ATM is a serine/threonine protein kinase that monitors the DNA damage throughout the cell cycle. ATM/ATR is recruited and activated by DNA double-strand breaks. Subsequently, ATM phosphorylates p53 and results 
in dissociation of p53 from its transcription repressor MDM2. Since aspirin can help to disrupt p53-MDM2 interaction to promote $\mathrm{p} 53$-mediated cell apoptosis [18], Asplatin, a $\mathrm{Pt}^{\mathrm{IV}}$ complexed with an aspirin, exhibited up to ten-times more cytotoxicity to tumor cells [19] and is so far the most effective $\mathrm{Pt}^{\mathrm{IV}}$ prodrug.

In drug activity, the recognition between biological molecules with metal ions can often be more important than with their complexed counterparts. All reported small molecular vanadium complexes are within a factor of 1000 of the potency of the PTP $1 \mathrm{~B}$ inhibitor. Of these, the best are intrinsic metal ions (i.e., $\mathrm{H}_{2} \mathrm{VO}_{4}^{-} / \mathrm{VO}_{3}{ }^{-}$) in presence of a substrate peptide DADEYL [20]. For antidiabetic vanadium complexes, evidence suggests that the role of the ligands is to deliver the active vanadium species to their target enzymes/proteins [21,22]. For example, vanadate $\left(\mathrm{H}_{2} \mathrm{~V}^{\mathrm{V}} \mathrm{O}_{4}^{-}\right)$to PTP1B with stability constants of $\operatorname{lgK}=6-8[23]$ and vanadyl ions $\left(\mathrm{V}^{\mathrm{VI}} \mathrm{O}^{2+}\right)$ to heat shock protein family (e.g., HSP60 and Grp78) with $\operatorname{lgK}=13-15$ [14]. To avoid nonspecific binding (normally $\operatorname{lgK}=4-7$ ), it is preferable to use vanadyl complexes with stability constants in the range of $\operatorname{lgK}=8-12$ for targeting HSPs; as can be seen in our recently prepared derivatized nitrilotriacetic acid vanadyl complexes ([VO(p-hpada)] [15] and [VO(p-dmada)] [16]) which showed significantly improved therapeutic index, with stability constants of $\operatorname{lgK} \sim 11$.

\section{Conclusion}

In conclusion, we postulate that for future research into metal-based pharmaceuticals, a successful strategy may favor prodrugs targeting the cellular stress responses (Figure 1B), with ligands helping to deliver metal ions to target proteins. Small molecules helping to promote stress response signaling (the enhancer) and/or prevent metal toxicity (the antidote) may be incorporated into the ligand structure. We believe this proposed prodrug strategy can lead to further metallodrugs with a high specificity and high efficacy for clinical applications.

\section{Financial \& competing interests disclosure}

Supported by National Natural Science Foundation of China (NNSFC; project no. 21571006 and 21771010). The author has no other relevant affiliations or financial involvement with any organization or entity with a financial interest in or financial conflict with the subject matter or materials discussed in the manuscript apart from those disclosed.

No writing assistance was utilized in the production of this manuscript.

\section{References}

1. Rosenberg B, Van Camp L, Trosko JE, Mansour VH. Platinum compounds: a new class of potent antitumour agents. Nature 222(5191), 385-386 (1969).

2. Levina A, Crans DC, Lay PA. Speciation of metal drugs, supplements and toxins in media and bodily fluids controls in vitro activities. Coord. Chem. Rev. 352, 473-498 (2017).

3. Wang K. The analogy in chemical and biological behavior between nonessential ions compared with essential ions. S. Afr. J. Chem. 50(4), 232-239 (1997).

4. Fulda S, Gorman AM, Hori O, Samali A. Cellular stress responses: cell survival and cell death. Int. J. Cell Biol. doi:10.1155/2010/214074 (2010).

5. Gao Z, Zhang C, Yu S, Yang X, Wang K. Vanadyl bis-acetylacetonate protected $\beta$ cell from palmitate-induced cell death through unfolded protein response pathway. J. Biol. Inorg. Chem. 16(5), 789-798 (2011).

6. Shen C, Li Z, Yang X, Wang K. La ${ }^{3+}$ binds to BiP/GRP78 and induces unfolded protein response in HepG2 cells. Chem. Biol. Interact. 176(2), 196-203 (2008).

7. Wu Y, Huang M, Zhao P, Yang X. Vanadyl acetylacetonate upregulates PPAR- $\gamma$ and adiponectin expression in differentiated rat adipocytes. J. Biol. Inorg. Chem. 18(6), 623-631 (2013).

8. Cun S, Li H, Ge R, Lin MC, Sun H. A histidine-rich and cysteine-rich metal-binding domain at the C terminus of heat shock protein A from Helicobacter pylori implication for nikel homeostasis and bismuth susceptibility. J. Biol. Chem. 283(22), 15142-15151 (2008).

9. Simmons SO, Fan C-Y, Yeoman K, Wakefield J, Ramabhadran R. NRF2 oxidative stress induced by heavy metals is cell type dependent. Curr. Chem. Genomics 5(1), 1-12 (2011).

10. Hao Z, Lou H, Zhu R et al. The multiple antibiotic resistance regulator MarR is a copper sensor in Escherichia coli. Nat. Chem. Biol. 10(1), 21-29 (2014).

11. Wang D, Lippard SJ. Cellular processing of platinum anticancer drugs. Nat. Rev. Drug Discov. 4(4), 307-320 (2005).

12. Zhao P, Yang X. Vanadium compounds modulate PPAR- $\gamma$ activity primarily by increasing PPAR- $\gamma$ protein levels in mouse insulinoma NIT-1 cells. Metallomics 5(7), 836-843 (2013).

13. Thompson KH, Lichter J, LeBel C, Scaife MC, McNeill JH, Orvig C. Vanadium treatment of type 2 diabetes: a view to the future. J. Inorg. Biochem. 103(4), 554-558 (2009). 
14. Niu X, Xiao R, Wang N et al. The molecular mechanisms and rational design of anti-diabetic vanadium compounds. Curr. Topics Med. Chem. 16(8), 811-822 (2016).

15. Wang N, Wang Z, Niu X, Yang X. Synthesis, characterization and anti-diabetic therapeutic potential of novel aminophenol-derivatized nitrilotriacetic acid vanadyl complexes. J. Inorg. Biochem. 152, 104-113 (2015).

16. Niu X, Yang J, Yang X. Synthesis and antidiabetic activity of new N,N-dimethylphenylene diamine-derivatized nitrilotriacetic acid vanadyl complexes. J. Inorg. Biochem. 177, 291-299 (2017).

17. He L, Wang X, Zhao C, Zhu D, Du W. Inhibition of human amylin fibril formation by insulin-mimetic vanadium complexes. Metallomics 6(5), 1087-1096 (2014).

18. Huang L, Chi CW, Cheng KW, Rigas B. Phospho-aspirin-2 (MDC-22) inhibits estrogen receptor positive breast cancer growth both in vitro and in vivo by a redox-dependent effect. PLoS ONE 9(11), e111720 (2014).

19. Cheng Q, Shi H, Wang H, Min Y, Wang J, Liu Y. The ligation of aspirin to cisplatin demonstrates significant synergistic effects on tumor cells. Chem. Commun. (Camb.) 50(56), 7527-7430 (2014).

20. Crans DC. Antidiabetic, chemical and physical properties of organic vanadates as presumed transition-state inhibitors for phosphatases. J. Org. Chem. 80(24), 11899-11915 (2015).

21. Levina A, Lay PA. Stabilities and biological activities of vanadium drugs: what is the nature of the active species? Chem. Asian J. 12(14), 1692-1699 (2017).

22. Levina A, McLeod AI, Gasparini SJ et al. Reactivity and speciation of antidiabetic vanadium complexes in whole blood and its components: the important role of red blood cells. Inorg. Chem. 54(16), 7753-7766 (2014).

23. McLauchlana CC, Peters BJ, Willsky GR, Crans DC. Vanadium-phosphatase complexes: phosphatase inhibitors favor the trigonal bipyramidal transition state geometries. Coord. Chem. Rev. 301(49), 163-199 (2015). 